\title{
Wall Optimisation - A Case Study From the Fimiston Open Pit, Kalgoorlie Consolidated Gold Mines
}

\author{
A.J. Beer Coffey Mining Pty Ltd, Australia (formerly Kalgoorlie Consolidated Gold Mines Pty Ltd)
}

M.R. Morrongiello Kalgoorlie Consolidated Gold Mines Pty Ltd, Australia

\begin{abstract}
During 2006, Kalgoorlie Consolidated Gold Mines' (KCGM) Geotechnical Section led a wall optimisation project for the Fimiston Open Pit. The 2006 stage of the project was aimed at bringing this increase into the 'probable reserve' category. The 2006 project has also identified the further studies which will be necessary to move this reserve increase up to the 'proven' category.

The project re-assessed assumptions made in a 1989 report, based on near-surface exposures. Observed pit wall structures and behaviour led to the decision to re-evaluate the optimum wall angle. For the first stage of the project, mainly existing data has been used, and primarily rock mass property data collected since 1990, but also structural data from the mapping of the old underground workings. The results from a major groundwater modelling project provided information as to the location of the phreatic surface which was used as an input to the modelling.

For the 2006 stage of the project, probability of failure was calculated using Rosenblueth's (1975) Point Estimation Method to pick values for rock mass parameters. These values were then used to generate shearnormal functions for the rock mass which provided input parameters to the SLIDETM package (Rocscience, 2005), the probability of failure being obtained from the mean and standard deviation of the factors of safety so derived.
\end{abstract}

\section{Introduction}

\subsection{KCGM overview}

KCGM is a joint venture between Barrick Gold and Newmont, each partner owning $50 \%$ of the company. The company has two operations adjacent to one another, the Fimiston open pit (known as the 'Superpit') and the underground Mt Charlotte operations, which are located on the eastern side of the City of KalgoorlieBoulder as shown in Figure 1.

Mining has been taking place in Kalgoorlie-Boulder since the discovery of gold in 1893 . Up to 80 mines have exploited the Fimiston deposit, with underground workings extending to a maximum depth of $1300 \mathrm{~m}$. These underground workings are being mined through by the current open pit operation and special working practices have had to be developed to allow continued safe operation within their vicinity.

The Fimiston open pit operation currently extracts around $800,000 \mathrm{oz}$ of gold per year, with a stripping ratio of around 7:1. The current pit is $3.5 \mathrm{~km}$ long, $1.5 \mathrm{~km}$ wide and around $450 \mathrm{~m}$ deep. 


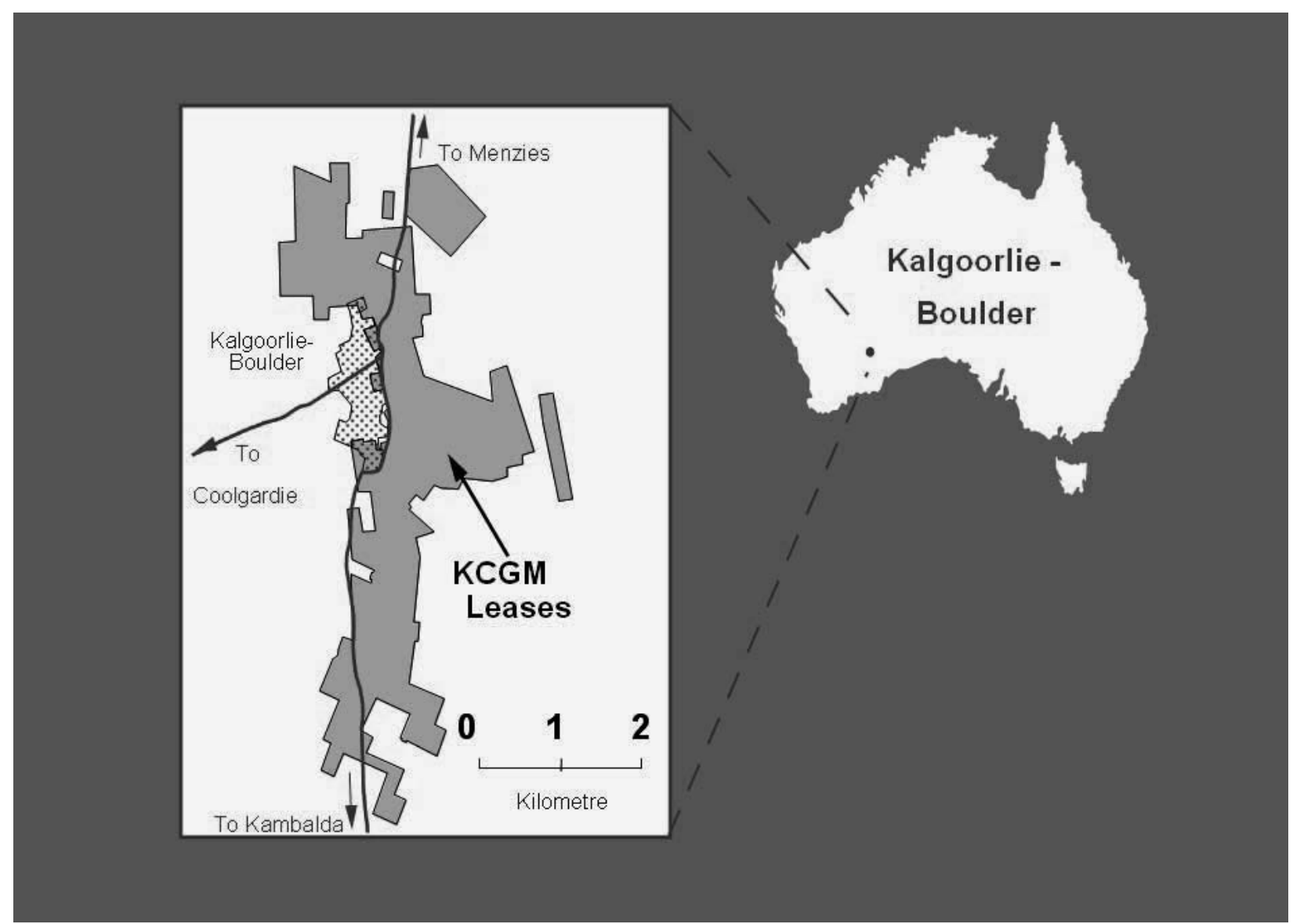

\section{Figure 1 Location of KCGM}

\subsection{Fimiston geology}

The Fimiston deposit is hosted within the Eastern Goldfields area of the Yilgarn Craton, within a greenstone belt. The local geology is shown in Figure 2.

The gold-bearing lodes are hosted by brittle-ductile shears and occur dominantly within the Golden Mile Dolerite, a differentiated intrusive unit. They are principally oriented north-south and have a steep westerly dip. The other major units found within the Fimiston open pit are the Black Flag Beds, the Williamstown Dolerite and the Paringa Basalt. This last unit will form most of the eastern wall of the final pit and is thus significant in the current study.

\subsection{Project background}

Various geotechnical studies conducted over the past 18 years have indicated that slope steepening may be possible; however many tended to conservative conclusions and/or attempted to extrapolate rock mass characteristics at depth from near-surface data. These reports variously addressed structural, rock material and rock mass properties for the area of the pit and data from these reports are included in the KCGM geotechnical database.

The use of the $65^{\circ}$ batters on the east wall of the pit (which have been used for pit design and ore reserve calculations up to the end of 2006) originated from one of these early reports, corresponding to the angle of the dominant foliation observed in near surface investigations. 


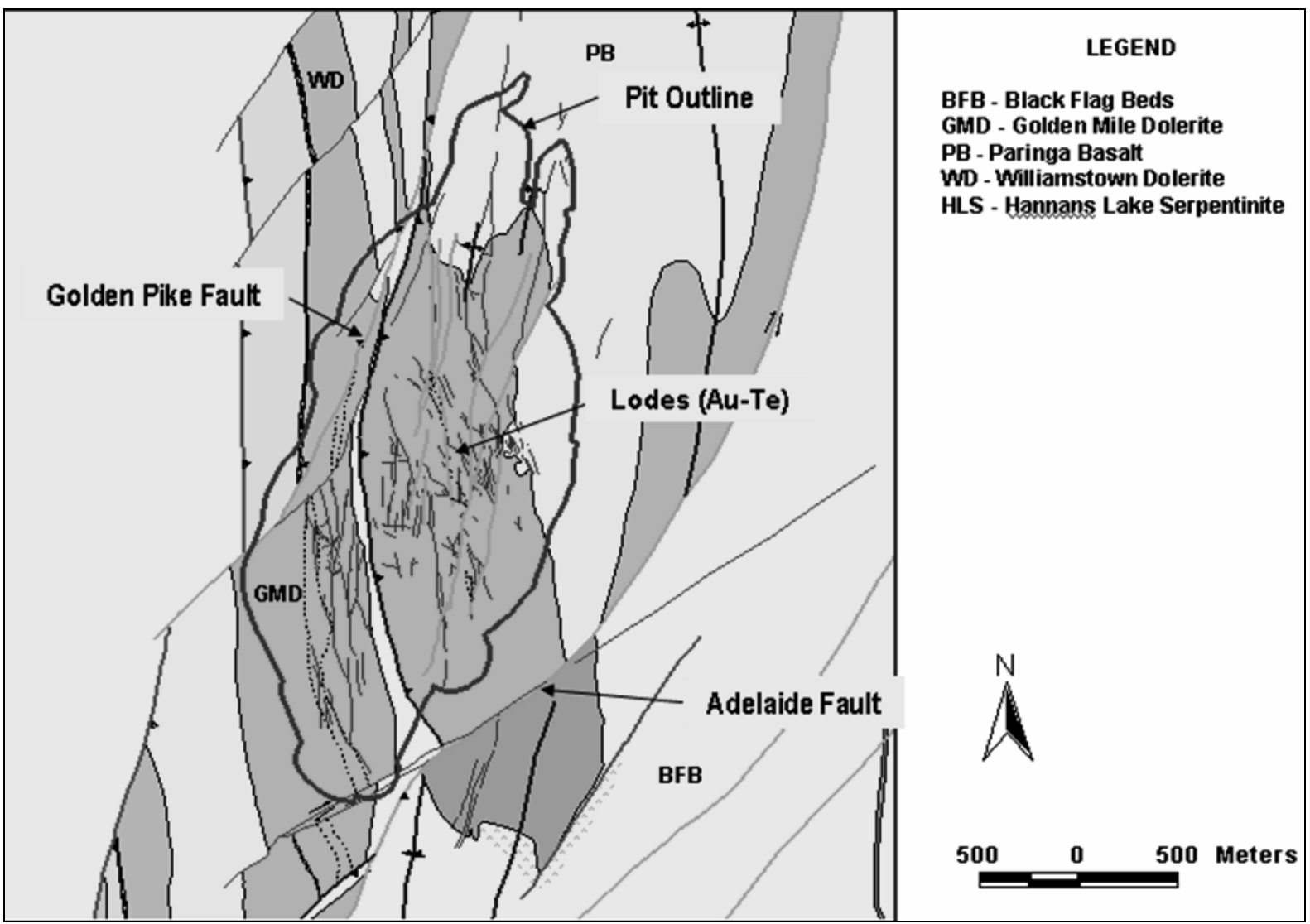

\section{Figure 2 Geology of the Fimiston deposit}

The assumption that the foliation observed near-surface continues to affect batter stability with increasing depth has been questioned before. A consultant's report from 2000 confirms the existence of the $65^{\circ}$ foliation in the east wall, but specifically stated that it was limited to the 'north end of the wall', an area which was explicitly excluded from this project due to a long history of instability. The report also described mixed results from trials of vertical batters on the east wall and concluded that batter steepening may be possible if 'continuous foliation planes do not exist'. The report also confirmed that $30 \mathrm{~m}$ high batters may be feasible on both the east and west walls of the pit.

The optimisation study described here has concentrated on the identified opportunity to steepen the east wall of the pit; the opportunity to re-evaluate the west wall design has also been identified, but does not form part of this project and is not described further here.

\section{Project outline}

\subsection{Previous assumptions and trials}

The life of mine (LOM) pit shell designs produced prior to 2006 had east walls which followed the eastward limits of mineralisation as closely as possible; however the use of $65^{\circ}$ batters on the east wall meant that some ore would have to be left unmined. Further cutbacks on the eastern wall were not possible to the presence of surface infrastructure.

Prior to the commencement of detailed design studies, wall steepening trials had been conducted on both the east and west walls of the pit, initially to assess the effect of using $30 \mathrm{~m}$ as opposed to $20 \mathrm{~m}$ batters when mining through stoped ground. On the east wall, batter steepening from 65 to $70^{\circ}$ was also trialled, as it was recognised that this would offer significant potential for increased ore recovery. One of the trial areas on the east wall is shown in Figure 3. It can be seen that the combination of $70^{\circ}$ batters with a $30 \mathrm{~m}$ batter height performs well, with only small-scale localised failure where sediment lenses occur within the Paringa Basalt unit. 


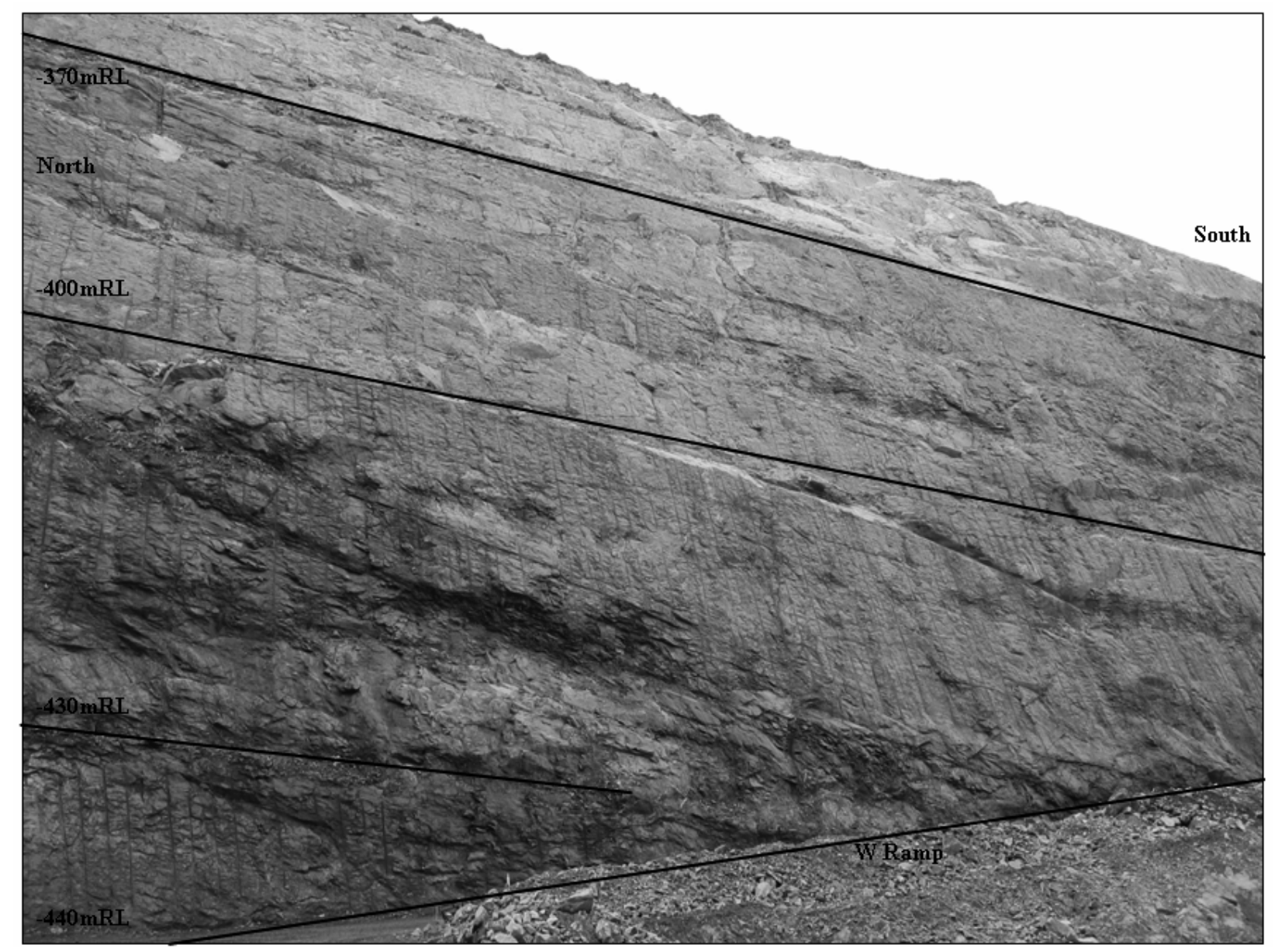

\section{Figure 3 Trial batters on the east wall of the Fimiston Open Pit}

With the potential for steepening of the east wall thus recognised, a conceptual design for a pit shell was produced using the revised east wall parameters of $70^{\circ}$ batters with a $30 \mathrm{~m}$ batter height, which was the design evaluated by the geotechnical study.

\subsection{Conceptual design}

The conceptual design produced for the wall optimisation study is shown in Figure 4. By steepening the east wall from previous designs, it proposed constructing the revised east wall principally within the Paringa Basalt unit. This allowed for greater excavation of the Golden Mile Dolerite Unit, with its contained lodes, and thus increased ore recovery.

The northern part of the east wall was excluded from the wall-steepening study, as it was recognised that unfavourably-oriented major structures present in that part of the wall would preclude the possibility of any re-design.

From a geotechnical viewpoint, the critical part of the conceptual design was the lowermost part of the wall around the $48500 \mathrm{~m}$ Northing. This part of the design proposed an inter-ramp angle of $55^{\circ}$ over a $360 \mathrm{~m}$ height. 


\section{Lithology Key}

\section{PB - Paringa Basalt}

GMD -Golden Mile dolerite BFB - Black Flag Beds

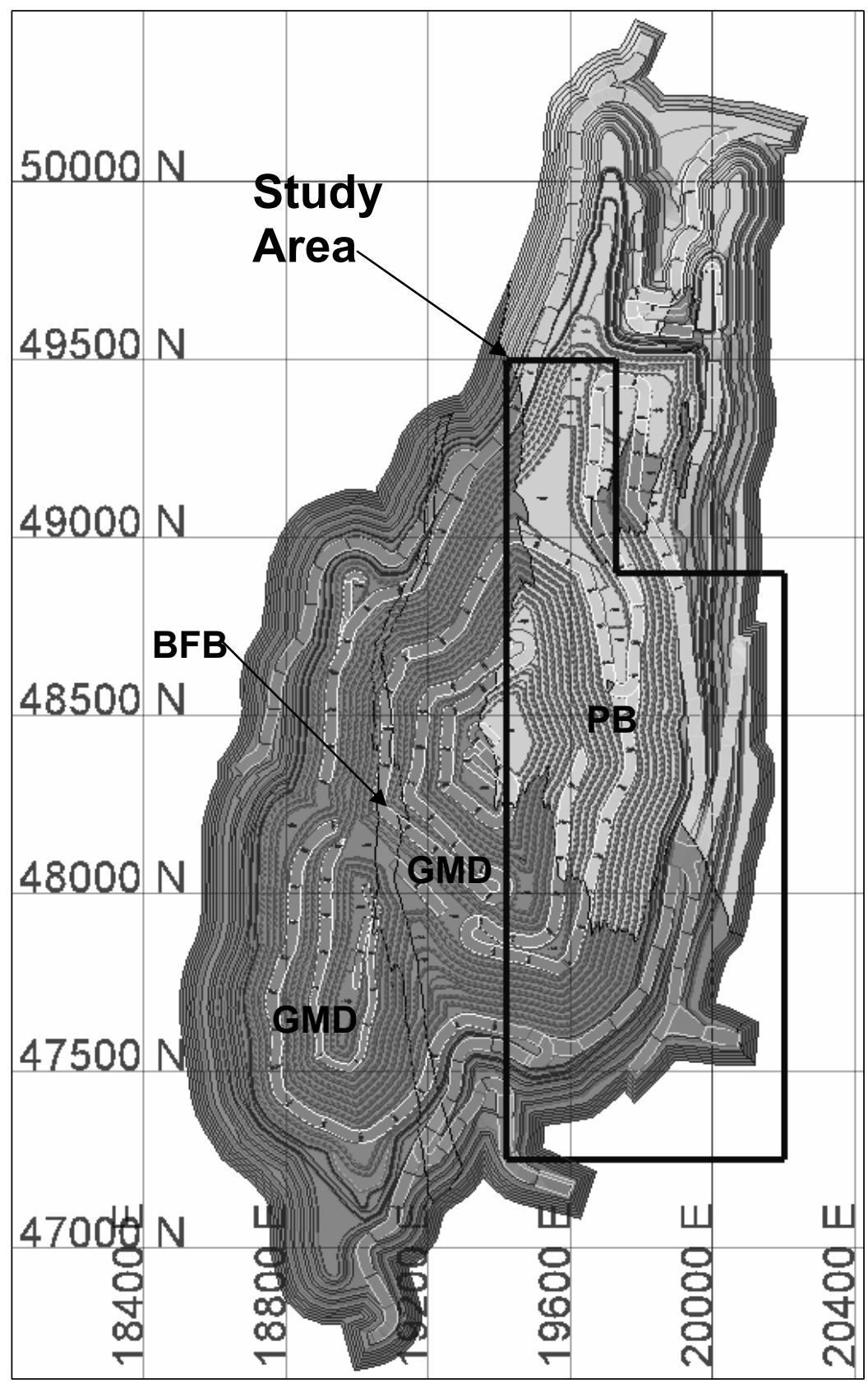

Figure 4 Conceptual design for east wall (study area shown outlined)

\subsection{Project components}

It was recognised that, before the commencement of the geotechnical study, the potential increased ore which could be mined using the conceptual design was in the inferred resource category. It was decided to adopt a phased approach to the project; the objective of the first phase being to bring the ore into the probable reserve category. A second phase, which would likely involve more detailed and costly geotechnical work, would bring the ore into proven reserve category. The exact nature of the work required in the second phase would be determined by the first phase results, which would enable priority areas for detailed investigation to be identified. An important factor in adopting this approach was the large amount of existing data which were available for analysis without the need for a costly drilling program.

The overall project structure is shown in Figure 5. Before the commencement of geotechnical studies, it can be seen that the project had already reached the end of phase 1A with a conceptual design and an inferred resource. The project described here is essentially phase $1 \mathrm{~B}$; the studies undertaken to bring the ore into probable reserve category. 


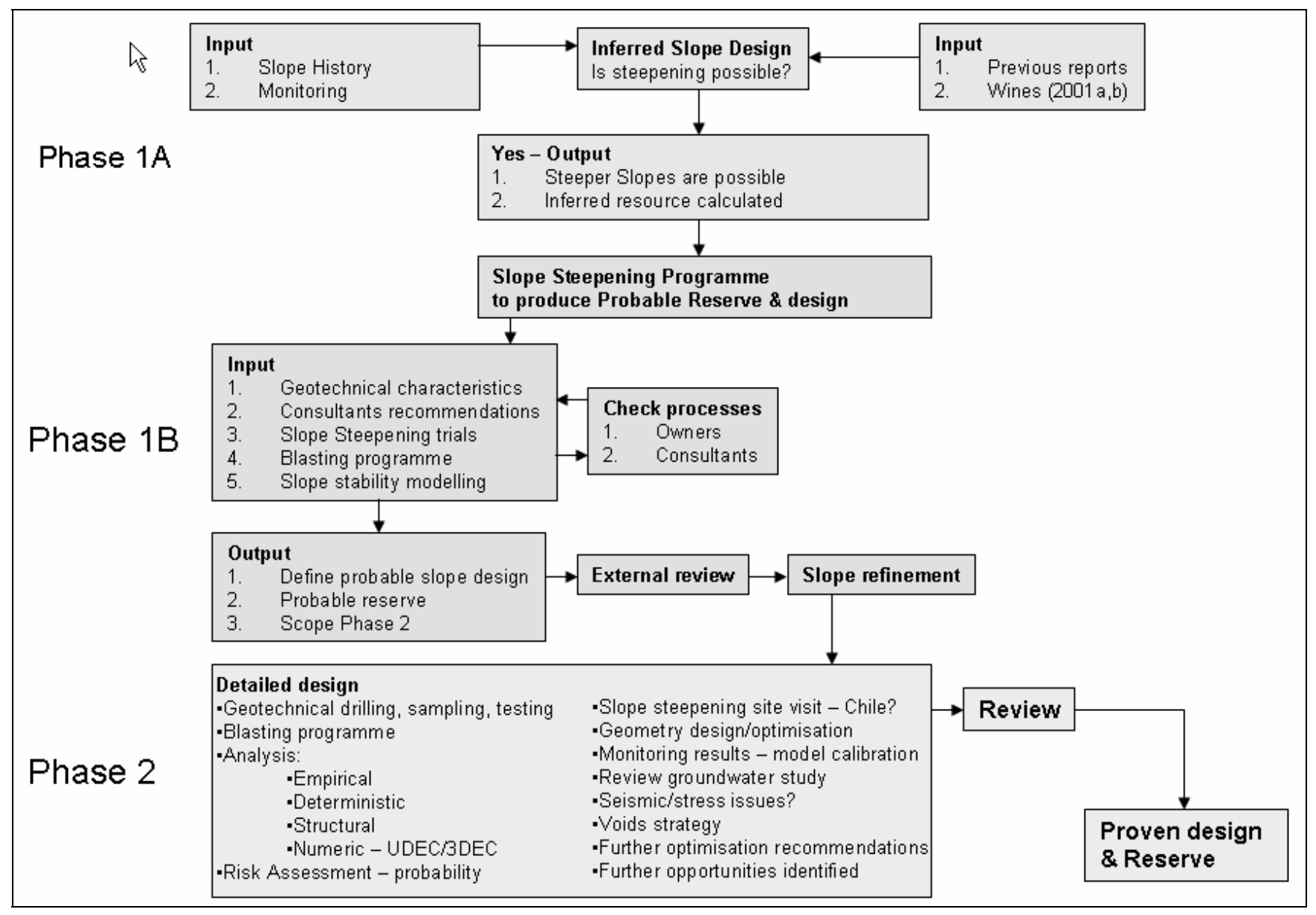

Figure 5 Slope design process used for wall optimisation project

The components of phase 1B of the project were determined to be:

- Empirical and experiential analysis of proposed and existing slopes and walls.

- Major structure analysis.

- Kinematic analysis of lesser structures.

- Groundwater analysis.

- Numerical analysis.

The studies concentrated on the critical (i.e. the most aggressive) section of the conceptual design east wall, the $360 \mathrm{~m}$ high slope at $48,500 \mathrm{mN}$. These are described in the next section.

\section{Wall optimisation project studies}

\subsection{Available data}

Two important data sources were available for the study area, which made the phase 1B assessment of the stability of the conceptual design east wall possible without further collection of field data; firstly, mapping data from the old underground workings which shows lithological boundaries and mineralised structures, and secondly, an exhaustive compilation of data collected and interpreted by Wines (2001a, 2001b) for a previous cutback design in the study area. The underground mapping data had largely been digitised as part of the on-going improvements in the Fimiston geotechnical database and was thus in a format suitable for rapid analysis. Wines' work compiled GSI, UCS and $\mathrm{m}_{\mathrm{i}}$ data for the rock mass in both the Golden Mile Dolerite and the Paringa Basalt for the east wall of the pit, and also evaluated statistical distribution 
parameters for this data, which were to prove invaluable in assessing probability of failure for the conceptual design.

\subsection{Empirical and experiential analysis}

From Wines' work, a mining rock mass rating (MRMR) for the Paringa Basalt, in which the critical slope is to be excavated, of 59 was obtained. Using the Haines (1993) empirical design chart, a design inter-ramp slope angle and slope height of $360 \mathrm{~m}$ indicates that further geotechnical studies are required to determine the stability or otherwise of such a design.

A report by Stacey (2004) compared the wall configurations with those of existing and planned operations, and the conceptual design configurations were not found to lie outside the range of planned or existing open pit configurations in terms of slope height and overall slope angle.

Experience at another West Australian mine, Sunrise Dam, indicates that walls of $250 \mathrm{~m}$ inter-ramp height at an inter-ramp slope of $59^{\circ}$ are achievable with care as shown in Figure 6.

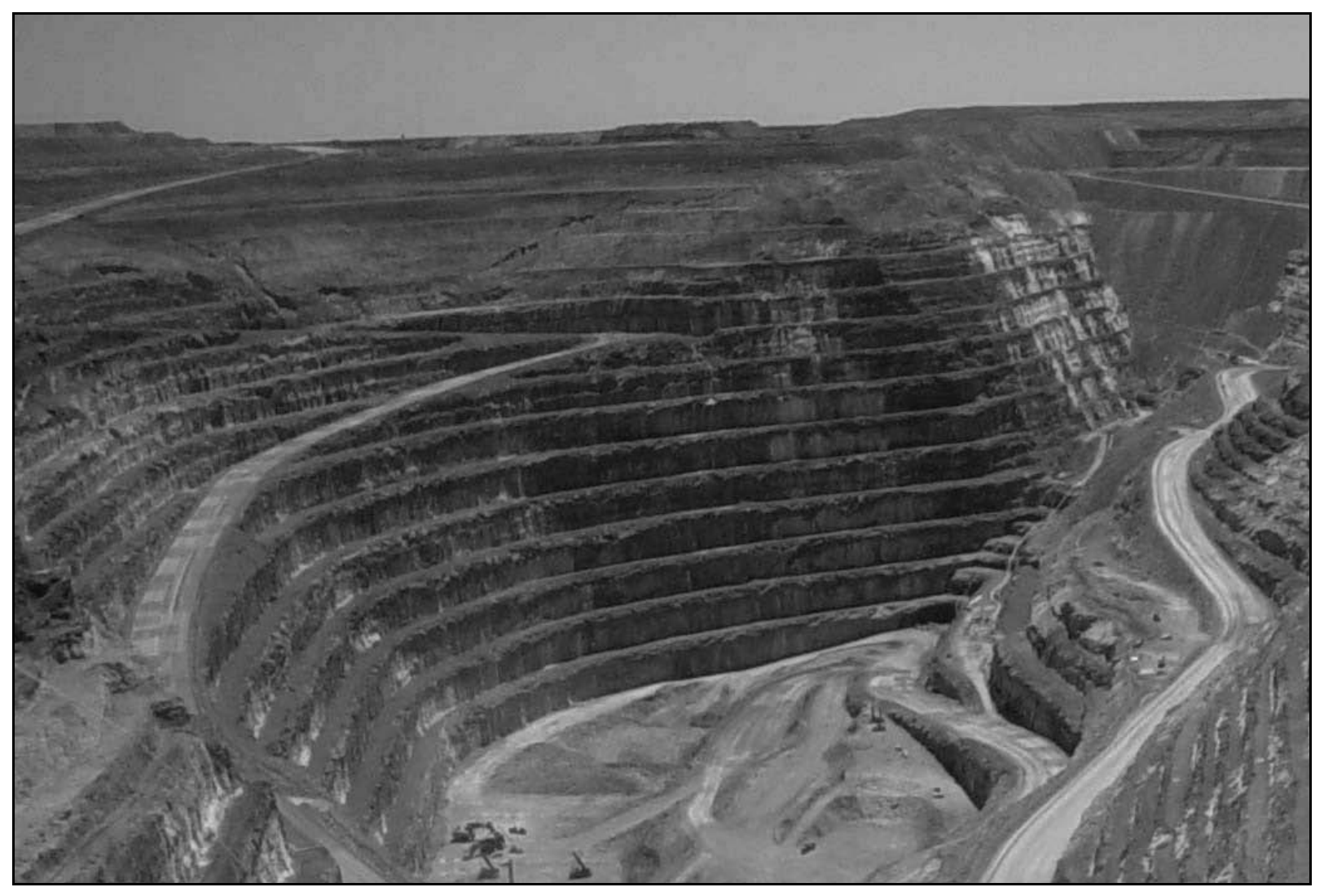

Figure 6 Open pit at Sunrise Dam, showing $250 \mathrm{~m}$ wall at $59^{\circ}$ overall angle

Furthermore, experience with the trial batters excavated on the east wall of the Fimiston pit indicated that these were stable on the small scale at least, as previously discussed. Automated prism monitoring of the east wall had indicated that rates of movement of the wall were steady, although showing increased rates as mining passed through the monitored level, with rates slowing once again as the mining level moved below the monitored level, as shown in Figure 7. 


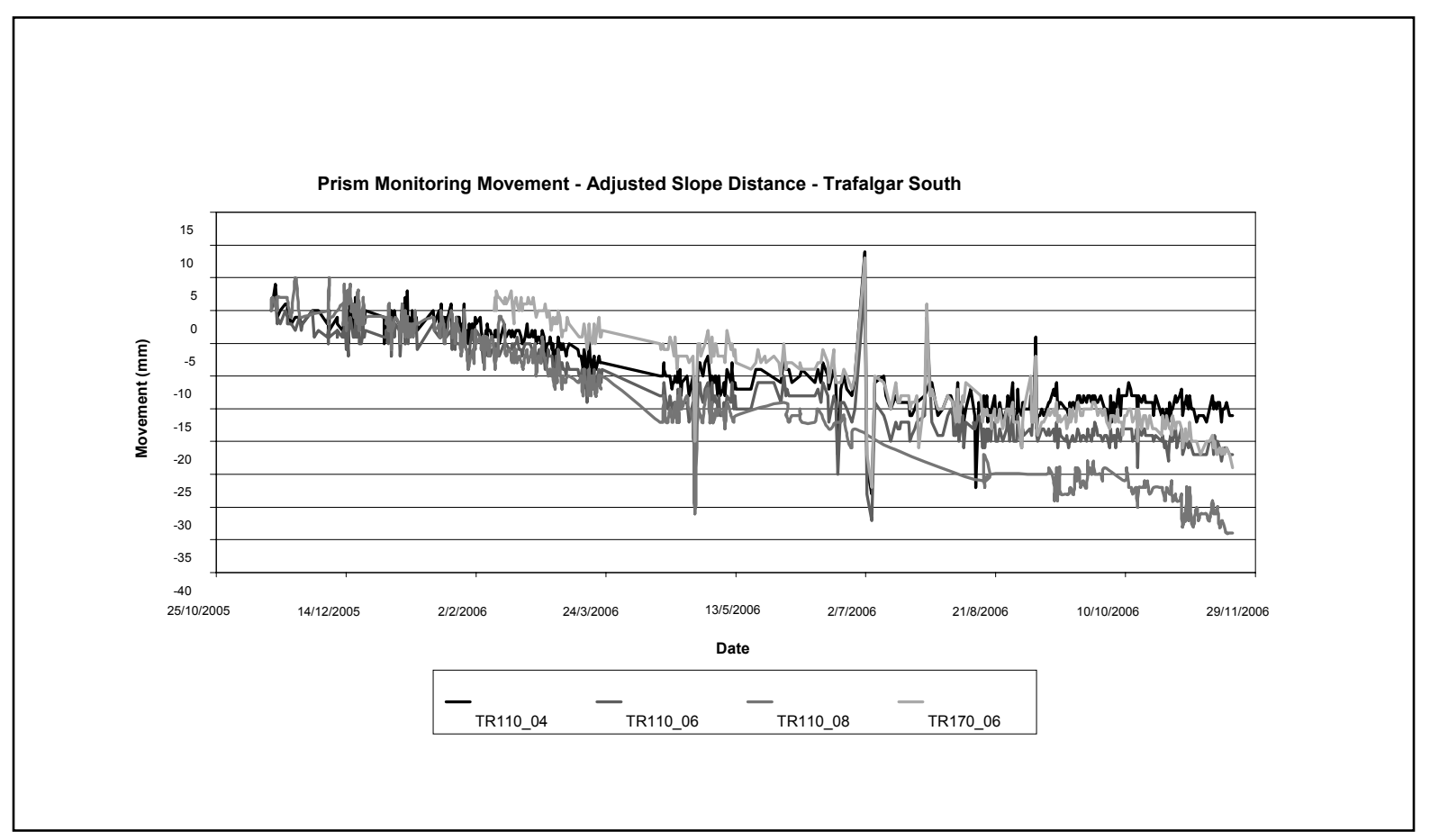

Figure 7 Prism monitoring plot for east wall of Fimiston open pit mine

\subsection{Major structure analysis}

Major structures are identified during drilling by the geology section at KCGM, and incorporated into the geological model for the pit. The 2006 structural model was constructed by Pickens (2006) from drillhole data and the underground mapping referred to above. A section through the model at the 'critical slope' northing of $48500 \mathrm{~m} \mathrm{~N}$, with the conceptual design pit section, is shown in Figure 8.

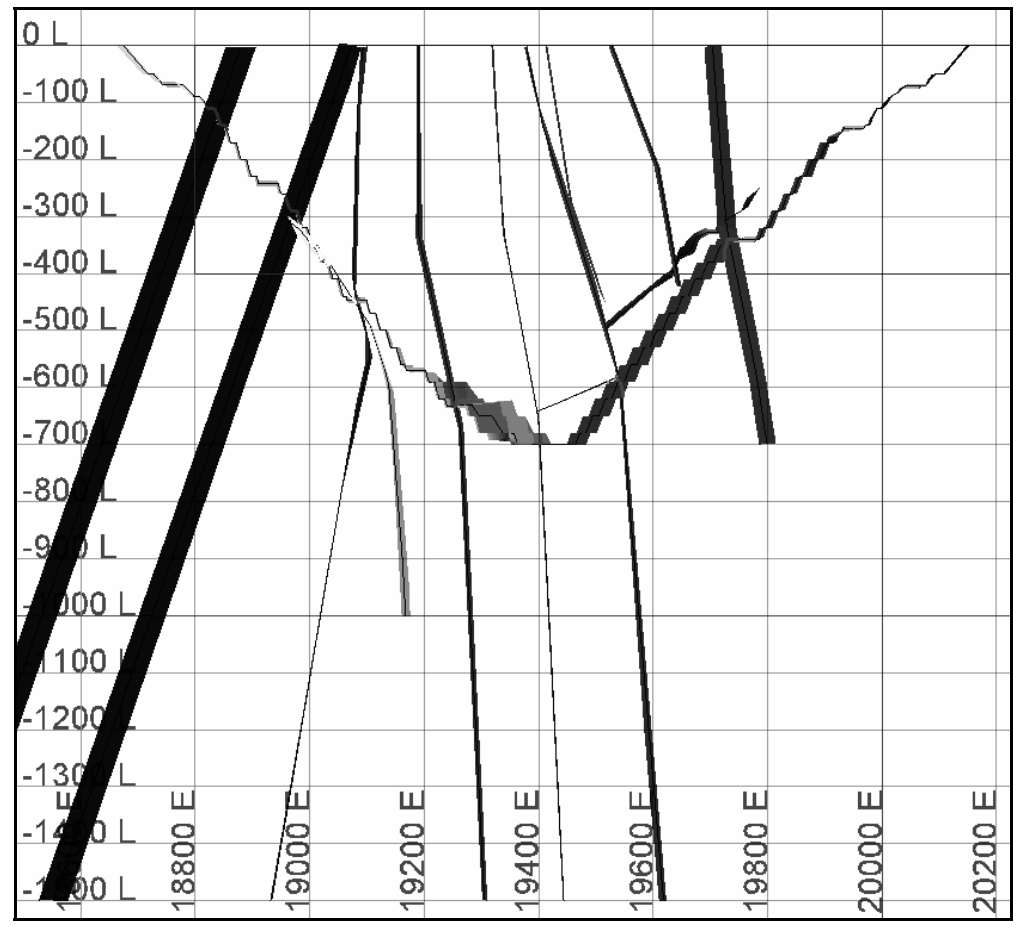

Figure 8 Section through major structure model for Fimiston open pit (from Pickens, 2006) 
It can be seen that all of the modelled major structures either dip eastwards into the slope, or are fully excavated by the conceptual design. Large scale failure along such surfaces was thus not anticipated.

\subsection{Kinematic analysis}

Using the digitised data from the underground level plans, stereonet plots were generated for the study area. Due to the large amount of data available, it was found that subdividing the study area into blocks, horizontally and vertically, gave stereonets which could be more easily interpreted, as the full data set gave a very 'cluttered' plot. An example of a plot for one of these blocks is shown in Figure 9.

The distribution of joint sets shown in Figure 9 is typical of the study area. Plots for the other blocks show little difference from Figure 10, although the discontinuity set labelled 1 is not apparent on the plots for the more southerly blocks. Although this particular discontinuity set is unfavourably oriented with respect the both the current and conceptual design slope, experience with the trial batters has shown that large scale failure along this structure does not occur. This discontinuity set corresponds to the plane of the inter-flow sediment lenses shown in Figure 3.

The stereoplot also indicates the possibility of wedge failures on a combination of joint surfaces; again experience shows that these occur at the small scale (normally berm crest only) and do not produce larges scale failures.

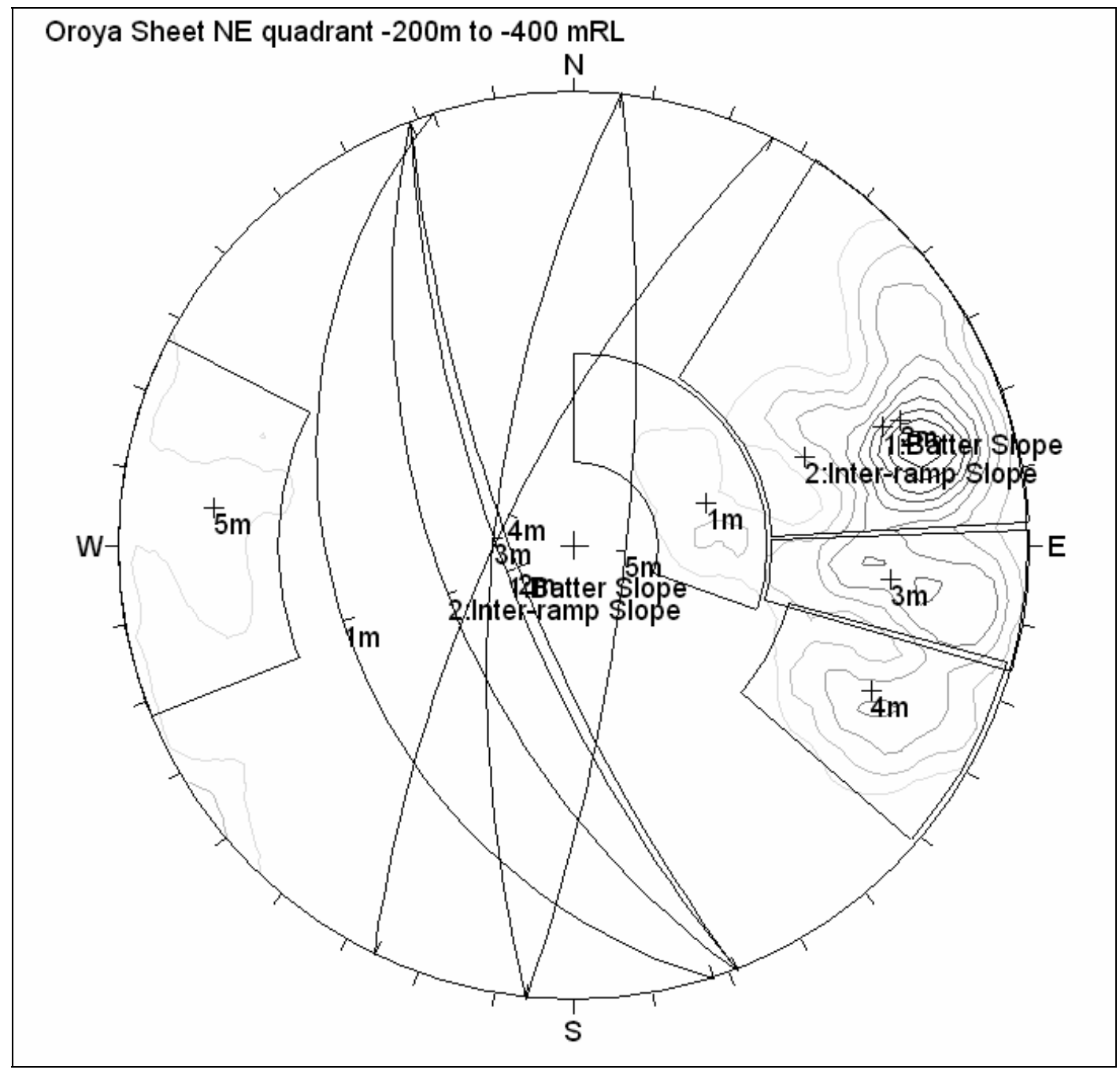

Figure 9 Sample stereonet plot for one of the study area blocks 


\subsection{Groundwater modelling}

As part of pit abandonment studies, a pit lake study was carried out by Zhan (2006) using a groundwater model developed by one of the authors (Morrongiello, 2003). The uniquely extensive underground workings which surround the Fimiston open pit give rise to an extremely good hydraulic connectivity; which necessitates pumping from one location only, a shaft at the southern end of the pit.

Monitoring of several bores around the periphery of the pit as groundwater has been allowed to rise from its underground mining level to the open pit design level of $710 \mathrm{~m}$ below mine datum allowed calibration of the groundwater model. An unusual feature of the groundwater 'surface' is that the lateral extent of the cone of depression generated by pumping does not vary with the depth to which water is pumped, but rather the cone truncates as the water level rises. This is due to the control of the shape of the cone of depression by the distribution of the underground workings. This control was verified by the modelling undertaken by Zhan (2006). A section through the groundwater model is shown in Figure 10.

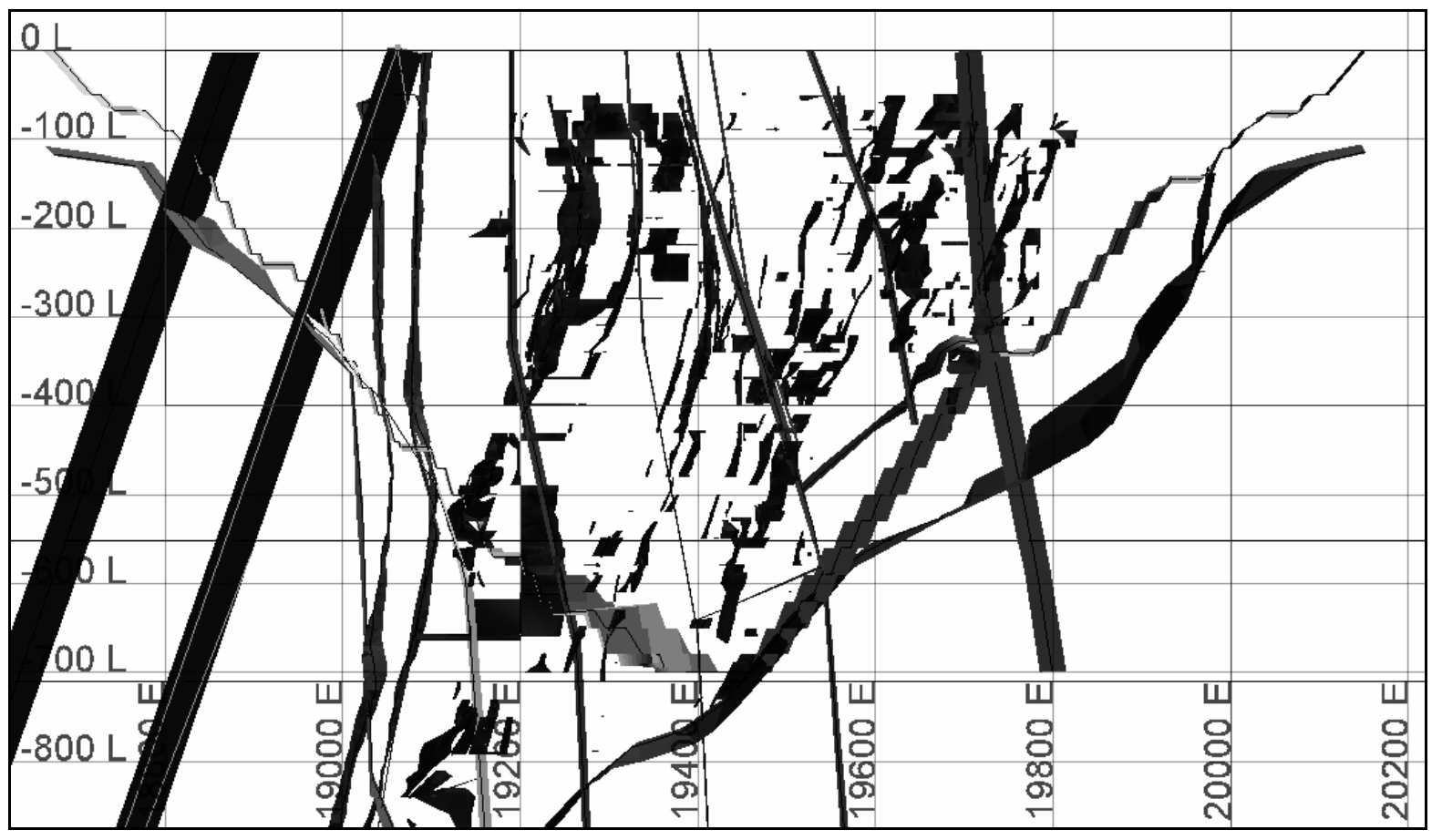

Figure 10 Section through groundwater model for Fimiston open pit, superimposed on 2006 conceptual pit design shell, at the 'critical slope' northing of $48500 \mathrm{~m} \mathrm{~N}$

The groundwater modelling enabled phreatic surfaces to be generated for both the design level of pumping during active mining, and for the case after mining ceases (the pit lake case).

\subsection{Numerical analysis}

Two dimensional limit equilibrium analyses were performed for a variety of scenarios on the critical slope. Deterministic analyses were carried out with the SLIDE ${ }^{\mathrm{TM}}$ (Rocscience, 2005) package using the mean HoekBrown failure criterion $\mathrm{m}$ and $\mathrm{s}$ values for the rock mass obtained by Wines (2001a, b), varying the phreatic surface from its current measured level to the predicted level post-closure. The model used with the measured phreatic surface is shown in Figure 11. A 'worst-case' scenario of a fully saturated pit slope was also modelled. Monte-Carlo simulations were also run using the statistical distributions of the $\mathrm{m}$ and $\mathrm{s}$ values determined by Wines (2001a, b).

Following a discussion with Gary Dempers of Dempers and Seymour Pty Ltd, the model was refined by generating shear-normal functions using the statistical parameters for the GSI and UCS values for the rock mass described Wines (2001a) and following the procedure described by Hoek and Brown (1997). By generating shear-normal functions for values of GSI and UCS +/- 1 standard deviation from the mean values, four shear normal curves could be plotted (shown ++, +-, -+ and -- on Figure 12). Rosenblueth's point 
estimation method (PEM) (Rosenblueth, 1975) could then be used on the results of the direct input of these shear-normal functions to the SLIDE ${ }^{\mathrm{TM}}$ program to determine the mean FOS and probability of failure of the slope.

The analyses are described in detail in three internal reports by Beer (2006 a, b, c). The factors of safety obtained are all well above 1, averaging around 1.8 using the Hoek-Brown shear strength criterion; the formation of a pit lake actually marginally increases the factor of safety due to the nature of the permeability of the pit walls. As maximum and minimum values for the $\mathrm{m}$ and $\mathrm{s}$ parameters determined by Wines were used in the Monte-Carlo simulations, probabilities of failure of 0 were obtained for all of the analyses described in Beer (2006a). Monte-Carlo simulations for the fully saturated model gave a probability of failure of $10 \%$.

The analyses using the shear-normal functions to model rock mass strength gave a higher mean factor of safety (2.3) for the slope and a probability of failure of $2 \%$ (Beer, 2006c). A seismic loading factor equivalent to a 4.5 Richter magnitude event was also applied to the models using the shear normal functions and the factor of safety and probability of failure remained constant to within one decimal point.

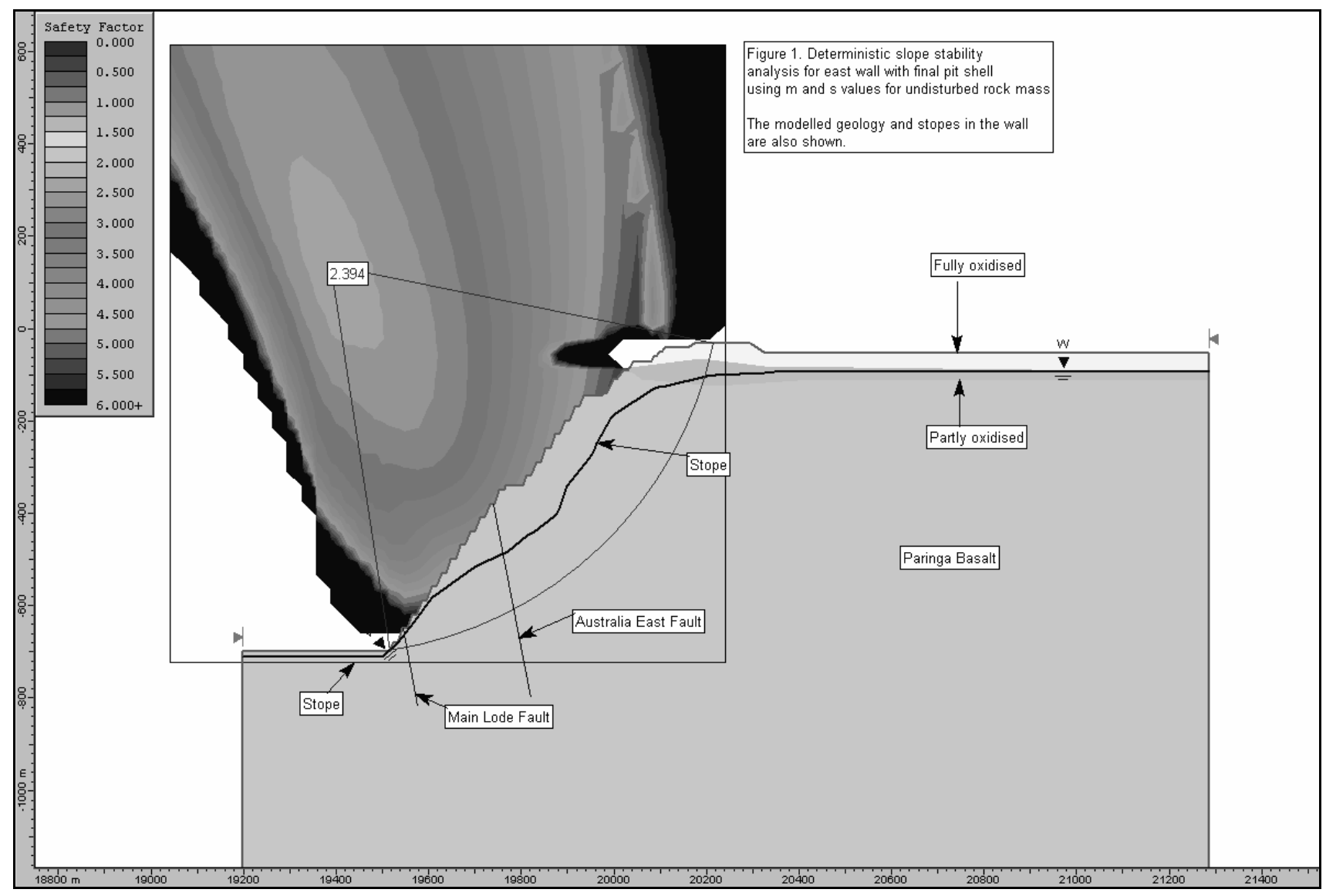

Figure 11 Critical slope model used in SLIDE ${ }^{T M}$ analyses (Beer, 2006a)

\subsection{External review}

The studies described above were reviewed by discussion with Dempers, G. (2006, pers. comm.), who contributed to the slope stability analysis as described above, and also by Sarunic (2006). Various other aspects, including wall performance and overall appearance, and the importance of well-controlled blasting, which have not been described here were considered. The need to extend the modelling to use software such as UDEC in phase 2 was confirmed, as was the importance of continued wall monitoring to assess pit performance. 
The high factors of safety obtained by this phase 1 modelling have identified a potential opportunity for further wall steepening, should the results of phase 2 of the project be favourable. While this may not potentially increase the ore reserve, it has the potential to decrease the stripping ratio and thus increase profitability.

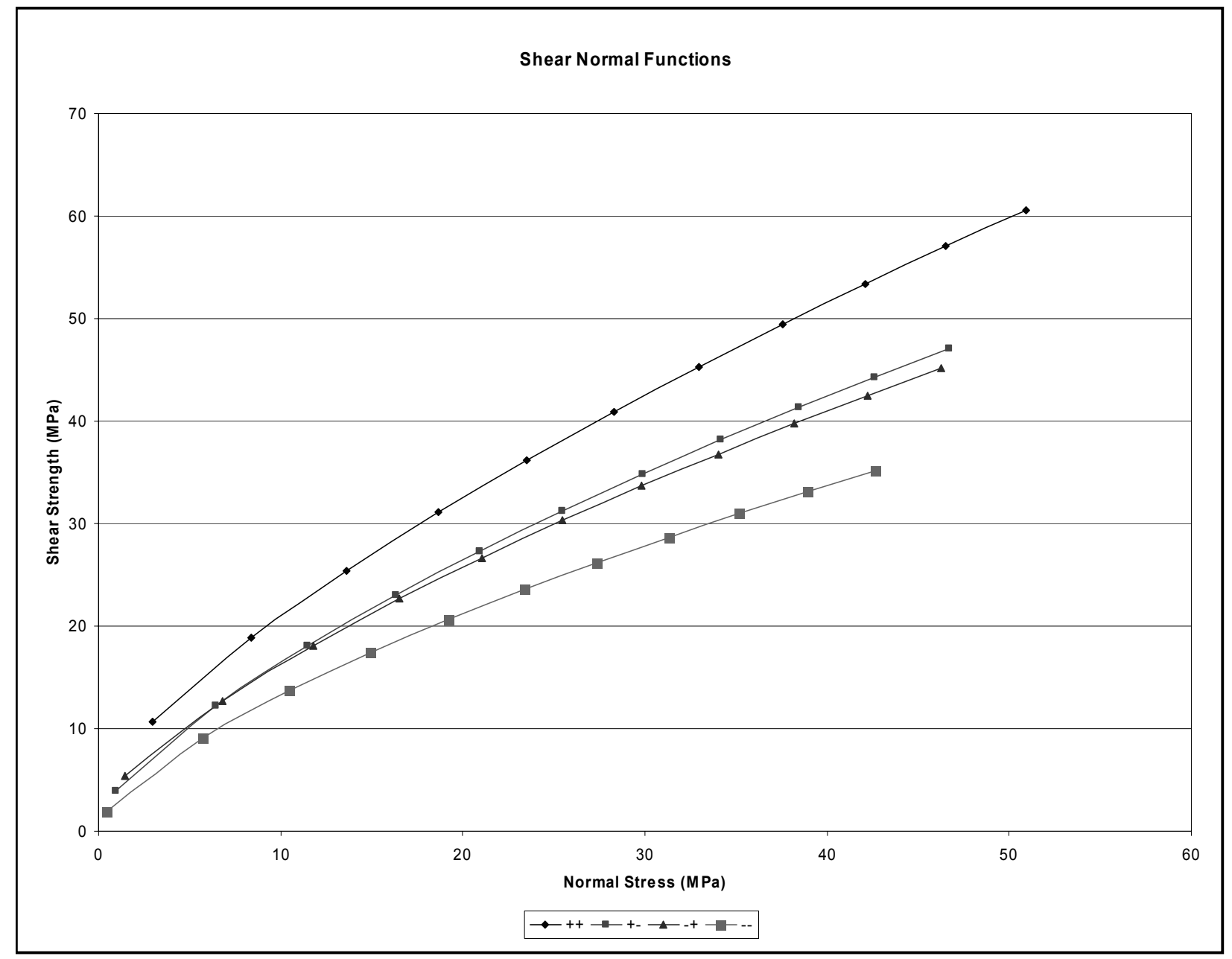

Figure 12 Shear normal functions developed for use in SLIDE ${ }^{\mathrm{TM}}$ analyses (Beer, 2006c)

\section{Conclusions}

The wall optimisation project has now entered phase 2, which seeks to confirm the results of phase 1 by more detailed modelling using finite element methods as recommended by the external consultants. Further data collection, interpretation and test work is also anticipated in this phase. The design wall configurations for other parts of the pit will also be reviewed to identify potential further opportunities for re-design.

The combination of information from a wide variety of sources has been used in this study. Much time was saved by the fact that a large amount of geotechnical information in the form of digitised underground plans and extracted discontinuity orientation data was already present in the geotechnical database at KCGM. The fact that the geological models are stored in a mine-wide format (VULCAN triangulations) meant that their import into the conceptual pit design was a matter of seconds. The use of the groundwater model, which was originally developed for pit closure studies for the Environmental section, is a good example of the potential synergy between geotechnical and environmental studies for a mining operation. The fact that a very large volume of rock property data had been compiled and statistical parameters evaluated, which provided direct input into the numerical modelling part of the study, serves to demonstrate that well-directed student projects can play a significant part in strategic geotechnical studies. 


\section{References}

Beer, A.J. (2006a) Slope Stability Modelling of East Wall Re-design October 2006. Unpublished Internal KCGM Report.

Beer, A.J. (2006b) Slope Stability Modelling of East Wall Re-design October 2006. Addendum. Unpublished Internal KCGM Report.

Beer, A.J. (2006c) Slope Stability Modelling of East Wall Re-design October 2006. Addendum 2. Unpublished Internal KCGM Report.

Haines, A. (1993) Rock Slope classification for the optimal design of monitoring networks. In Proceedings of the Australian Conference on Geotechnical Instrumentation and Monitoring in Open Pit and Underground Mining, T. Szwedzicki (ed.), Kalgoorlie, Western Australia, 21-23 June 1993, Balkema, Rotterdam, pp. 201-209.

Hoek, E. and Brown, E.T. (1997) Practical estimates of rock mass strength. International Journal of Rock Mechanics \& Geomechanics Abstracts. 34(8), pp. 1165-1186.

Morrongiello, M. (2003) 2003 Fimiston Groundwater Report. Unpublished KCGM Geology internal report.

Pickens, G. (2006). Fimiston Structural Model 2006. Unpublished KCGM Report 2006.

Rocscience (2005) SLIDE Version 5.0, Rocscience Inc., Ontario, Canada, http://www.rocscience.com.

Rosenblueth, E. (1975) Point Estimates for Probability Moments. Proceedings of the National Academy of Science of the USA, 72 (10).

Sarunic, W. (2006) Geotechnical Review for the Trafalgar Cutback. Unpublished Memo Report from Snowden Mining Consultants dated 21st December 2006.

Stacey, P.F. (2004) Pit Slope Stability Review - November 2004. Unpublished Letter report from Stacey Mining Geotechnical to KCGM.

Wines, D.R. (2001a) Aspects of Rock Slope Engineering at the Fimiston Open Pits. Unpublished MSc Thesis, Curtin University of Technology.

Wines, D.R. (2001b) Geotechnical Status Report Oroya Cutback. Unpublished KCGM Geotechnical internal report.

Zhan, J. (2006) Kalgoorlie Consolidated Gold Mines Fimiston Pit Lake Water Balance Model. Unpublished Barrick Report 2006. 